\title{
Effects of signaled reward in instrumental conditioning: Enhanced learning on DRL and DRH schedules of reinforcement
}

\author{
ROGER M. TARPY and JEAN E. ROBERTS \\ Bucknell University, Lewisburg, Pennsylvania
}

\begin{abstract}
The effects of signaled reward were examined using DRL and DRH schedules of reinforcement. In each case, one group of rats received a brief cue between the reinforced response and the reward, and a second group received brief cues at random times. With the DRL schedule (Experiment 1), signaled reward decreased response rate, increased response efficiency (number of responses per reinforcer), and increased resistence to satiation relative to the control group. With the DRH schedule (Experiment 2), signaled reward increased response rate, efficiency, and resistance to satiation. These results refute an overshadowing explanation of the effects of signaled reward and suggest that food-correlated cues enhance learning of the reinforcement contingencies.
\end{abstract}

Animals that respond on a variable-interval (VI) schedule of reinforcement and are given a brief cue prior to the delivery of reward respond at a much lower rate than control subjects which receive their brief cues independent of reward. This phenomenon was discovered by Pearce and Hall (1978) and St. Claire-Smith (1979) and has been the subject of a number of other investigations (e.g., Hall, 1982; Hall, Channell, \& Pearce, 1981; Mackintosh \& Dickinson, 1979; Williams, 1975, 1978; Williams \& Heyneman, 1982).

Pearce and Hall (1978) and St. Claire-Smith (1979) explained this phenomenon in terms of overshadowing: The food-correlated cue is a perfect predictor of reward, whereas the response is a relatively poor predictor (being only occasionally followed by food), so that the association between the response and the reward (the R-US association) is overshadowed by that between the stimulus and reward (the S-US association). The result is a reduced response rate in the condition with the foodcorrelated cue. This signaled-reward phenomenon has received a great deal of attention because it is one of the few pieces of evidence suggesting that responses can enter into associations with USs in essentially the same manner that stimuli enter into associative relations with USs, and that overshadowing can occur between two qualitatively different sorts of elements (a stimulus and a response), not just between two stimuli (see also Shettleworth, 1981).

Recent evidence, however, has not supported the original overshadowing interpretation. For instance, Tarpy, Lea, and Midgley (1983, Experiments 3 and 4; see also

\footnotetext{
These data were reported at the Eastern Psychological Association meetings at Baltimore, MD, in April 1984. We thank Xiaowen Han for help in running the subjects in Experiment 2. Reprints may be obtained from Roger M. Tarpy or Jean E. Roberts, Department of Psychology, Bucknell University, Lewisburg, PA 17837.
}

Roberts, Tarpy, \& Lea, 1984) showed that the phenomenon does not occur when a variable ratio (VR) schedule of reinforcement is used. The rate difference between the food-signal (correlated, or C) and random-signal (random, or R) groups should have occurred because the R-US and S-US correlations were as discrepant as they were in earlier studies that used VI schedules. It would appear therefore that a differential correlation is not sufficient to produce this effect. Such a conclusion, of course, undermines the essence of the overshadowing account of the phenomenon.

Other data refuting the overshadowing interpretation of the signaled reward phenomenon were reported by Roberts, Tarpy, and Lea (1984). The general purpose of their study was to test the strength of the R-US association using an alternative measure of response strength, namely Nevin's resistance-to-disruption measure (see Nevin, 1974, 1979). After establishing the signaled-reward phenomenon, the authors tested for response strength during extinction or after the animals had been satiated. The relative change in response rate on these tests showed that the $\mathrm{C}$ subjects were actually more resistent to disruption than the $\mathrm{R}$ animals. That is, signaled reward had produced an increase in the strength of the R-US association rather than a decrease. In a similar experiment using VR schedules, no difference in response strength was obtained between the $\mathrm{C}$ and $\mathrm{R}$ conditions.

Roberts et al. explained their findings in terms of a series of propositions. First, the authors argued that subjects are engaged in causality detection, that is, that they learn about overall reinforcement contingencies in an effort to discover the putative causal factors of reward. Second, in accord with Tarpy et al.'s (1983) analysis (see also Tarpy, Roberts, Lea, \& Midgley, 1984), subjects learn about two causality sources on a VI schedule (responding and time) but only one source on a VR schedule (responding). Third, the correlated light serves to increase 
the learning of these contingencies, probably by enhancing the salience of or attention to the causality source that is "external" to the subject, namely the temporal interval offset. As a result, the VI-C animals have a stronger response-reinforcer association than the VI-R subjects, but, of course, the VR-C and VR-R animals are not affected by the cue. Finally, animals attempt to maximize reinforcers while minimizing energy expenditures within the constraints of their knowledge of the contingencies. Thus, relative to the VI-R animals, the VI-C subjects display greater efficiency during acquisition (lower response rate without a sacrifice in the reward rate), in addition to the stronger response strength on a resistance-to-disruption test, because subjects in the latter condition have learned the contingencies to a greater degree. In summary, Roberts et al.'s "efficiency" theory, which claims that signaled reward produces better response learning, is in sharp contrast to the overshadowing explanation, which contends that the correlated signal causes poorer response learning.

The purpose of the present experiments was to provide further evidence that would be consistent with the "efficiency" theory of Roberts et al. In particular, the following studies investigated the effects of signaled reward in situations using two other schedules of reinforcement. Both schedules included contingencies based on the passage of time; thus, according to our efficiency theory, we would expect a food-related cue to enhance learning in both cases. The way in which superior learning is manifested, however, should differ as a function of the schedule demands. Using a differential reinforcement of low rates (DRL) schedule (Experiment 1), better learning should be manifested by a lower response rate, greater efficiency (fewer responses per reinforcer), and greater resistance to disruption. In contrast, using a differential reinforcement of high rates (DRH) schedule (Experiment 2), better learning should be manifested by a higher response rate, greater efficiency, and greater resistance to change. The overshadowing interpretation, on the other hand, would predict lower response rates in the $\mathrm{C}$ condition regardless of the reinforcement schedule.

\section{EXPERIMENT 1}

Experiment 1 explored the effects of signaled reward in a DRL schedule of reinforcement (see, e.g., Kramer \& Rilling, 1970). We should note that both the overshadowing and efficiency hypotheses predict a lower rate of responding for the correlated subjects relative to the random animals. However, the overshadowing interpretation, which stipulates a weaker response-reinforcer association with signaled reward, would expect other evidence of poorer performance, for example, a decrement in the efficiency and/or number of reinforcers earned and less resistence to disruption. Our interpretation, on the other hand, would predict other evidence of better performance, for example, more earned rewards, greater ef- ficiency (fewer responses per reinforcer), and greater resistance to disruption.

\section{Methods}

Subjects. The subjects were 16 female Long-Evans rats raised in the colony at Bucknell University. They were approximately 110 days old and weighed between 206 and $247 \mathrm{~g}$ at the beginning of the experiment. The subjects were housed individually in standard wire-mesh cages and given free access to water throughout. They were food-deprived prior to the experiment and were fed a sufficient quantity of lab chow each day following their session in order to maintain body weight at about $85 \%$ of the preexperimental weight.

Apparatus. Eight identical lever boxes were used. Each was manufactured by Coulbourn Instruments and measured $30 \mathrm{~cm}$ long $\times 25.5 \mathrm{~cm}$ wide $\times 29 \mathrm{~cm}$ high. The boxes were housed in larger sound-attenuating chambers, each of which was equipped with a ventilating fan. The lever manipulandum in each box was located directly over the Coulbourn food trough in the center of the front wall (12 cm above the grid floor). Three jewel lights were positioned $3.5 \mathrm{~cm}$ above the lever (the central yellow light served as the cue). In addition, a houselight was centered at the top of the front wall $2 \mathrm{~cm}$ below the ceiling. Rewards were $45-\mathrm{mg}$ food pellets (P. J. Noyes Co., standard diet). All of the lever boxes were programmed by an Apple computer located in an adjacent room.

Procedure. Prior to differential treatment, all subjects were placed in the apparatus for about $4 \mathrm{~h}$ and given magazine shaping. This consisted of the delivery of a pellet every $20 \mathrm{~min}$, in addition to the reinforcement of leverpresses on an FI 5-sec schedule. One hundred earned pellets constituted our shaping criterion. None of the animals required hand shaping, although some of the subjects did not meet the criterion on the first day and thus required an additional 4-h session on the following day.

Differential treatment began on the day after all subjects had met the shaping criterion. Eighteen 20 -min sessions were given on successive days. A DRL 5-sec schedule was in effect on the first two sessions and a DRL 10-sec schedule was used on the remaining days. In accordance with standard practices, either reinforcement delivery or any response that occurred within the specified time reset the computer clock; that is, the subjects could earn reward only by waiting the appropriate time following the last response (or the previous reward) and then pressing the lever.

Two major groups were designated. In the correlated (C) condition, a .5-sec light flash was given just prior to each reinforcer, that is, between the operative response and the pellet delivery. Whenever a $\mathrm{C}$ animal received this signal, a light was simultaneously presented to its yoked random $(R)$ partner. Thus, the $R$ subjects received the same number and temporal arrangement of lights as the $\mathrm{C}$ animals, but the lights were thoroughly independent of their behavior and of rewards. Random subjects, of course, were given the .5-sec delay of reward to insure that the temporal relationship between the response and reward was equivalent for both groups. The chambers were arranged physically in such a way that correlated and yoked boxes were not adjacent to one another; the $\mathrm{C}$ and $\mathrm{R}$ conditions were counterbalanced across the eight boxes.

Following the 18th session, all subjects were given free access to food for 5 days. On the 5 th day after this satiation period, they were given one additional test session with the same procedure as used in the DRL-10 sessions earlier. This final day provided a means for assessing the animals' resistance to disruption.

\section{Results}

It is well known that DRL schedules are relatively difficult for rats to learn; it normally takes considerable training before the appropriate temporal discrimination is made (e.g., see Gage, Evans, \& Olton, 1979). Since 
performance on the first 3 days of our experiment was extraordinarily erratic, we considered them to be a warmup period and we accordingly analyzed only the final 15 DRL-10 sessions.

The mean number of responses per minute for the last 15 sessions for the $C$ and $R$ groups is shown in Figure 1 (solid lines, left ordinate). A subjects $\times$ groups $\times$ sessions analysis of variance confirmed that the $R$ subjects generally pressed at a higher rate than the $\mathrm{C}$ animals $[F(1,14)=5.3, p<.05]$. The main effect of sessions was significant $[\mathrm{F}(14,196)=2.8, \mathrm{p}<.01]$, but the interaction between groups and sessions was not $(F<1.0)$.

The mean reinforcers per minute for each group are also shown in Figure 1 (dotted lines, right ordinate). An identical analysis on the reinforcement rates showed a significant main effect for sessions $[F(14,196)=21.5$, $p<$ $.001]$, but neither the main effect of groups $[F(1,14)=$ $2.2, \mathrm{p}>.05]$ nor the groups $\times$ sessions interaction $[\mathrm{F}(14,196)=1.5, \mathrm{p}>.05]$ was significant.

The efficiency hypothesis suggested by Roberts et al. (1984) explicitly predicts that the responses-per-reinforcer ratios will be lower in the $\mathrm{C}$ condition than in the $\mathrm{R}$ group. An analysis of variance on these ratios showed that they were, indeed, lower for the $\mathrm{C}$ animals (see Figure 2). In particular, there was a significant groups effect $[F(1,14)$ $=7.8, \mathrm{p}<.05]$ and a significant main effect of sessions $[F(14,196)=4.0, p<.01]$; the interaction was not reliable $(\mathrm{F}<1.0)$.

Finally, we analyzed the performance on the single test session for which the subjects were satiated. The mean response rate for the $\mathbf{R}$ subjects actually dropped below the level of that for the $\mathrm{C}$ animals ( 4.7 responses/min for the $C$ and 4.3 responses/min for the $R$ subjects). Relative to the final baseline session's response rates, therefore, the C animals' behavior was significantly less disrupted than the $R$ subjects' behavior: The mean percent

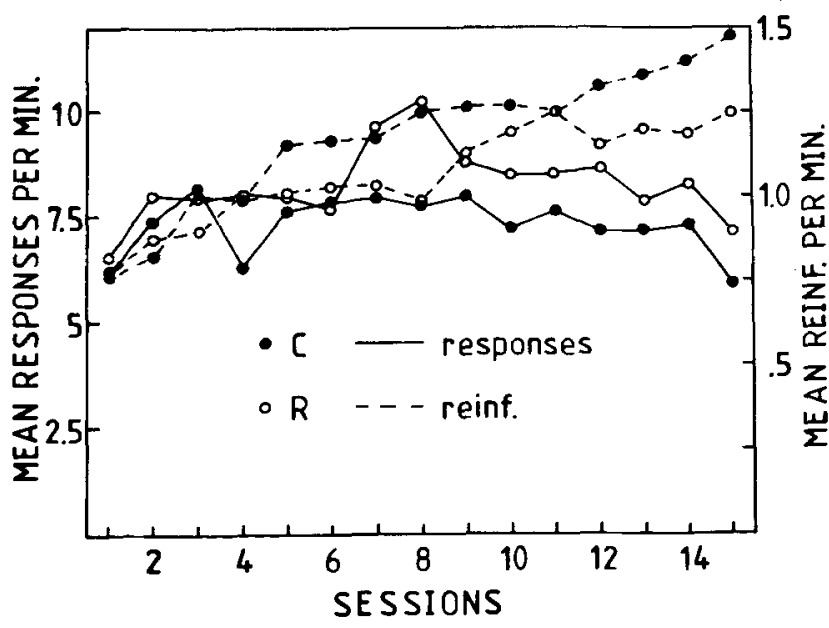

Figure 1. Mean responses per minute (solid lines, left ordinate) and mean reinforcers per minute (dotted lines, right ordinate) for the $\mathbf{C}$ (filled circles) and $\mathbf{R}$ (open circles) groups as a function of the last 15 DRL $10 \mathrm{sec}$ sessions in Experiment 1.

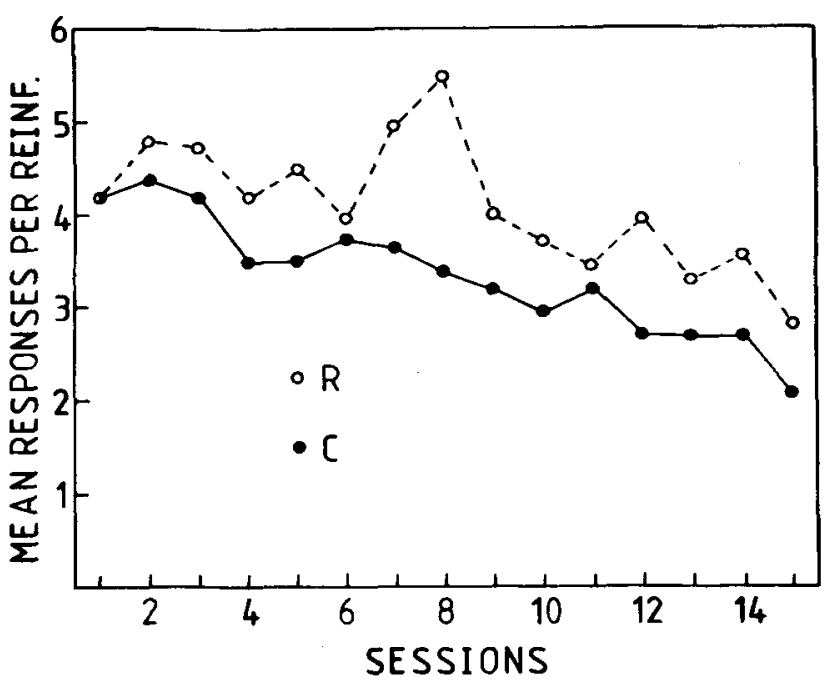

Figure 2. Mean responses per reinforcer (efficiency) for the $C$ and $R$ groups as a function of the last 15 DRL 10 sec sessions in Experiment 1 .

of baseline for the $\mathrm{C}$ group was $81.2 \%$, whereas the mean for the $\mathrm{R}$ group was $60.6 \%$. This difference was statistically reliable $[\mathrm{t}(14)=2.11, \mathrm{p}<.05]$.

\section{EXPERIMENT 2}

In Experiment 2, we investigated the effects of signaled reward in a DRH schedule of reinforcement. This schedule is especially interesting because, unlike the effects obtained with VI and DRL schedules, better learning of the temporal contingency should be manifested by a higher response rate rather than a lower one. Thus, we predicted that animals receiving food-correlated cues would not only respond more efficiently (fewer responses per reinforcer) and show greater resistance to satiation, but also respond at a higher rate than animals receiving random cues. This prediction, of course, is the opposite of that based on the notion of overshadowing, which always predicts a decreased rate of responding with signaled reward.

\section{Method}

Subjects and Apparatus. The subjects were 14 male Long-Evans rats raised in the colony at Bucknell University. They were about 125 days old and weighed between 380 and $440 \mathrm{~g}$ at the start of the experiment. They were housed and maintained as in Experiment 1 . The apparatus was the same as in Experiment 1.

Procedure. All animals were given preliminary magazine training as described in Experiment 1. During this phase, one $\mathrm{C}$ subject and one $R$ subject did not acquire the leverpress response and thus were eliminated from further testing and analysis. In the training phase of the study, the subjects were given 13 daily 20 -min sessions using a modified DRH schedule. The final phase of the study was the satiation test. All animals were given free access to food for $24 \mathrm{~h}$ immediately following the last acquisition session. Then, on the following day, they were tested using the same schedule as the one employed on the final acquisition day.

The DRH schedule was actually a fixed ratio three (FR-3) requirement that had to be completed within a certain period of time. The schedule operated as follows. A subject's first response started 
a clock in the computer; reinforcement was delivered after two additional responses had been emitted within the critical time period. If the subject failed to make the two additional responses within the specified time, the computer was "reset" and the subject had to initiate the FR-3, that is, start the clock, all over again. In other words, a subject could earn food only by responding with interresponse times (IRTs) that were sufficiently short to insure that two additional responses were executed within the required time. The time periods within which the FR-3 had to be completed decreased over successive days of acquisition. This was done because pilot research had indicated that subjects were unable to learn this very difficult task unless the times were shortened gradually. The values used on successive sessions were: infinity (no minimum time), 10 , $10,10,5,4,4,4,4,3,2,2$, and $.6 \mathrm{sec}$. The time value used on the satiation test was also $.6 \mathrm{sec}$.

All other conditions of this experiment were like those used in Experiment 1. In particular, the subjects were assigned to the $\mathrm{C}$ and $\mathrm{R}$ conditions such that counterbalancing over the boxes was achieved. The reinforcer was delayed for $.5 \mathrm{sec}$ after the operative response, during which time, for a given $\mathrm{C}$ subject, the pilot light was turned on. The light also flashed simultaneously in the yoked partner's box.

\section{Results and Discussion}

The mean response rates for the $\mathrm{C}$ and $\mathrm{R}$ groups are shown in Figure 3 (solid lines, left ordinate). An analysis of variance was used to assess the reliability of the effects. Although the $\mathrm{C}$ subjects did not respond at an overall faster rate than the $R$ subjects $[F(1,10)=1.4$, $\mathrm{p}>.05]$, the interaction between groups and sessions was significant $[\mathrm{F}(12,120)=2.34, \mathrm{p}<.01]$, as was the main effect of sessions $[F(12,120)=20.2, p<.001]$. This indicates that, in general, both groups increased their response rates over days of training and that the $\mathrm{C}$ subjects did so to a greater degree than the $R$ animals. A significant main effect of groups, of course, would have constituted even greater support for the efficiency theory. The

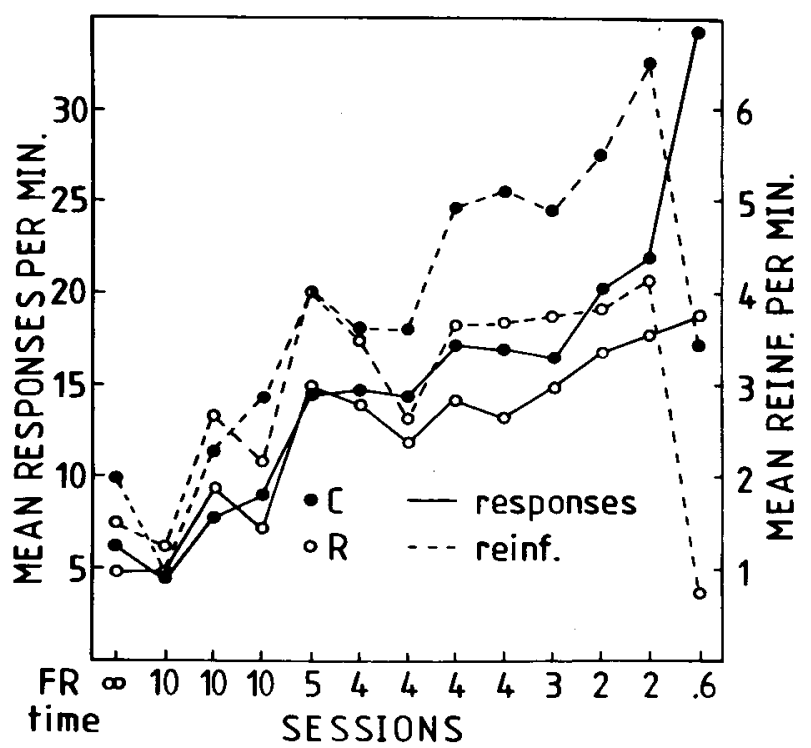

Figure 3. Mean responses per minute (solid lines, left ordinate) and reinforcers per minute (dotted lines, right ordinate) for the $\mathrm{C}$ (filled circles) and $R$ (open circles) groups as a function of the DRH sessions in Experiment 2. failure to note this effect, however, is easily explained in terms of task difficulty. As Figure 3 illustrates, when the response requirement was easy to master, both groups were able to respond at a high rate. However, as the task became more difficult, group differences were observed. Presumably, the $C$ subjects responded at a higher rate because their response association was sufficiently strong to tolerate such a disruptive contingency. On the last day of acquisition, when the task of making three responses within $.6 \mathrm{sec}$ was the most difficult, the difference in response rates was statistically significant. Thus, these data confirm our hypothesis by showing a reverse of the original signaled reward phenomenon: a food-correlated cue led to faster responding than in the random signal condition.

The rates of reinforcement are also shown in Figure 3 (dotted lines, right ordinate). It would appear from the figure that the $C$ subjects earned more reinforcers than the $R$ animals. The overall variability, however, was sufficiently high to prevent the main effect of groups $[F(1,10)$ $=2.2, \mathrm{p}>.05]$ and the groups $\times$ sessions interaction $[F(12,120)=1.7, p>.05]$ from being significant. The analysis did reveal a significant main effect of sessions $[F(12,120)=12.7, p<.001]$, and post hoc $t$ tests showed that a C-R difference existed on the last 3 days of training, with the $\mathrm{C}$ subjects earning more reinforcers than did $R$ subjects.

In order to assess performance efficiency, the ratio of responses to reinforcers during each session was computed for each subject. The group means are shown in Figure 4. All of the effects were significant [groups, $F(1,10)=8.3$, $\mathrm{p}<.05$; sessions, $\mathrm{F}(12,120)=16.0, \mathrm{p}<.001$; groups $X$ sessions interaction, $F(12,120)=6.7, p<.01]$. What these data show, therefore, is that the $\mathrm{C}$ subjects were, overall, more efficient in their responding and that the discrepancy in efficiency between the $\mathrm{C}$ and $\mathrm{R}$ conditions increased over training.

Finally, an analysis was performed on the satiation test data. As in Experiment 1, rate of response was converted into percent of acquisition baseline (last acquisition session). The mean percent was higher for the $\mathrm{C}$ subjects $(17.8 \%)$ than for the $\mathrm{R}$ animals $(\mathbf{7 . 8 \%})$, but the effect was not statistically reliable $[t(10)=1.5]$. An analysis of the raw response rates, however, did show that the $\mathrm{C}$ animals reponded more than the $R$ subjects $[t(10)=2.5, p<.05]$. We believe that the lack of difference on the ratio data may be due to a floor effect. In particular, the task of making three leverpresses within $.6 \mathrm{sec}$ was sufficiently daunting (or perhaps even aversive) to preclude very high levels of performance while fully satiated. Note, for example, that the DRL subjects in Experiment 1 performed at an average of $70.9 \%$ of acquisition baseline rates on the satiation test, whereas the DRH subjects dropped to an average of $12.8 \%$. In any event, the significant difference between $C$ and $R$ animals on the raw data is markedly inconsistent with an overshadowing interpretation and thus, in our opinion, lends strong support to the claim that response strength is indeed higher for the $\mathrm{C}$ subjects than for the $R$ subjects. 


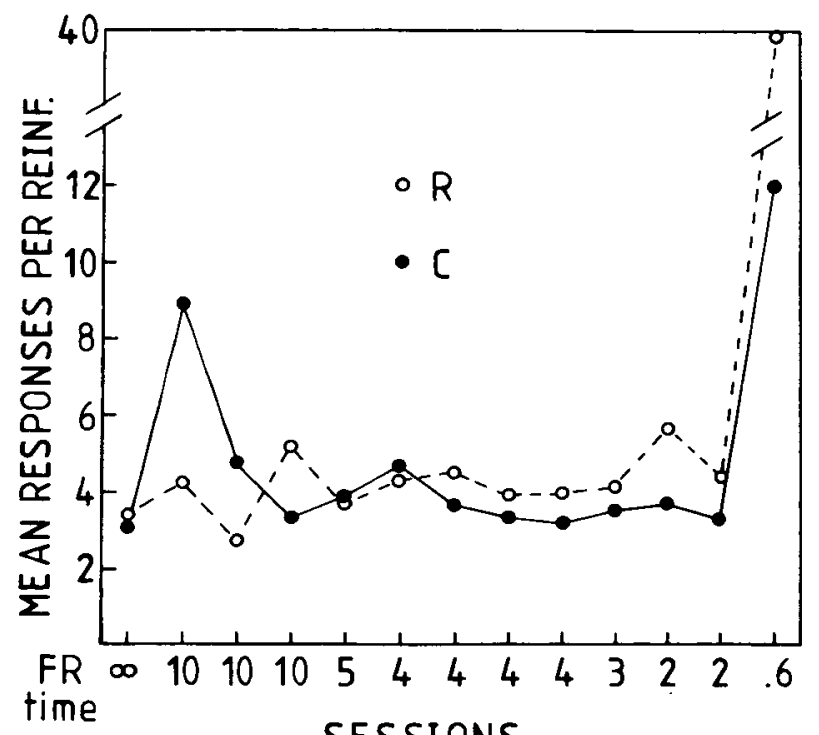

SESSIONS

Figure 4. Mean responses per reinforcer (efficiency) for the $\mathrm{C}$ and $R$ groups as function of the DRH sessions in Experiment 2.

\section{GENERAL DISCUSSION}

The present experiments demonstrated that signaled reward leads to a lower rate of responding on a DRL schedule but a higher rate on a DRH schedule. Both studies, furthermore, showed that performance was more efficient for the $\mathrm{C}$ animals, and both supported the notion that the response strength, that is, resistance to satiation, was higher following training with the correlated cue than following training with the random cue.

All of these outcomes are consistent with the propositions outlined in the introduction (see Roberts et al., 1984), and at least some of them fail markedly to support either the original overshadowing theory (Pearce \& Hall, 1978; St. Claire-Smith, 1979) or a modification of that theory proposed by Tarpy et al. (1983). Consider, for instance, the results of Experiment 1, which employed the DRL schedule of reinforcement. An overshadowing interpretation would predict a lower overall rate of response for $\mathrm{C}$ animals, but it presumably would not predict an increase in efficiency for the $C$ subjects relative to the $R$ animals. This is because a low rate of responding on a DRL schedule, while certainly more compatible with higher efficiency than a high response rate, does not ensure efficient performance. Rather, efficient responding on a DRL schedule entails learning a temporal discrimination such that paced responding is achieved. Furthermore, the overshadowing account is wholly incompatible with the increase in resistance to satiation of the $\mathrm{C}$ animals' behavior observed in this experiment.

The failure of the overshadowing theory is even more apparent when considering the results of Experiment 2, which employed the DRH schedule of reinforcement. The overshadowing hypothesis claims that the response- reinforcer association is weaker in the $\mathrm{C}$ than in the $\mathrm{R}$ subjects, and thus the response rate in the $C$ animals should be correspondingly lower. According to this theory, such a difference in performance should be evident on a DRH schedule as well. This did not occur. The $\mathrm{C}$ subjects had a higher response rate in addition to increased efficiency and resistance to change.

In summary, the results reported here, coupled with others reported by Roberts et al. (1984) and Tarpy et al. (1983), leave little doubt that the overshadowing interpretation is a wholly inadequate account of the signaled reward phenomenon. On the other hand, all these results are consistent with the suggestion of Roberts et al. that signaled reward produces enhanced learning both in terms of a stronger response (increased resistance to disruption) and in terms of increased response efficiency (decreased number of responses per reinforcer) within the constraints imposed by the schedule of reinforcement. Moreover, the fact that greater response efficiency was achieved through a lower rate in one experiment but a higher rate in the other experiment strengthens our claim considerably.

We previously stated our position (i.e., Roberts et al., 1984) in terms of a series of propositions (as opposed to a formal theory) partly because we lacked additional verification that food-related cues cause enhanced, not inferior, response learning and partly because we were unsure about the adequacy of any single mechanism by which a more formal theory might operate. It is now clear that signaled reward produces enhanced learning. The question that remains is how this superior learning is actually attained in this situation. We still cannot recommend an explanatory mechanism that is without problems, but several are highly plausible.

One possibility, suggested in the second and third propositions listed previously, is that the cue serves to enhance discrimination learning; that is, to enhance the salience of or attention to the temporal interval offset. This suggestion is especially compatible with the fact that $C-R$ differences occur with temporally based schedules of reinforcement (VI, DRL, DRH) but not with ratio schedules. It is also compatible with Tarpy et al.'s (1984) observation that an alternative method of enhancing the salience of the temporal interval, namely making it fixed, reduces response rates, the effect being significantly magnified by the presence of the correlated cue.

Another explanation of how the food-correlated cue might enhance learning is through potentiation (e.g., see Galef \& Osborne, 1978). When a compound stimulus is paired with an unconditioned stimulus, overshadowing or potentiation may occur between the two elements of the compound. In the present context, the light, in compound with the response, may potentiate the $\mathbf{R}$-food association. Of course, if this explanation is to be taken seriously, more will have to be known about when to expect overshadowing versus potentiation in normal Pavlovian conditioning.

Perhaps the most plausible mechanism by which the correlated cue might enhance learning is secondary reinforcement. Such a mechanism would certainly be consistent 
with the bulk of findings to date. A secondary reinforcer could cause better learning and facilitate performance in several ways. First, it could summate with the delayed primary reinforcer, causing an increase in the overall level of reward and, as a consequence, better learning. Second, a secondary reinforcer could provide immediate reinforcement and thus generate in $\mathrm{C}$ animals, but not in $\mathbf{R}$ subjects, the same behavioral outcomes that are normally associated with immediate primary reinforcement. It is well known, for example, that a brief cue occurring between the response and delayed reward facilitates delayed-reward performance (see Tarpy \& Sawabini, 1974, for a review). Third, a secondary reinforcer could bridge the temporal gap between the response and food in the same way that intervening cues operate in conventional Pavlovian conditioning experiments to produce a stronger response-reinforcer association (see Rescorla, 1982).

Any of these accounts could also apply if one assumed that the IRT, rather than the discrete leverpress, was the response unit being strengthened. For example, with the DRL schedule, long IRTs would be reinforced in greater magnitude (primary plus secondary reward) and/or at a shorter delay in the correlated condition. Note that this latter hypothesis differs significantly from the one proposed by Lattal and his associates (e.g., Lattal \& Ziegler, 1982; Sizemore \& Lattal, 1978), who claimed that, with a VI schedule, short IRTs are selectively reinforced in $\mathrm{R}$ subjects whereas the distracting effect of the correlated cue prevents short IRTs from occurring just prior to reward in the $\mathrm{C}$ subjects. This theory has trouble reconciling the effects of the cue on DRL versus DRH schedules: If the cue is said to distract the subject on DRL schedules, thus preventing short IRTs from being selectively strengthened, it is hardly logical to claim that the cue has the opposite effect on DRH schedules.

We do not see any way of choosing among these various secondary reinforcement hypotheses on the basis of the present data. Indeed, we see no reason why a secondary reinforcer wouldn't function in all of these ways simultaneously.

Is the concept of secondary reinforcement compatible with other known facts regarding this phenomenon? The answer is a qualified "yes." First, it is known that the correlated cue can indeed function as a secondary reinforcer (Pearce \& Hall, 1978, Experiment 4; St. ClaireSmith, 1979). Second, enhanced learning as a result of having received an immediate secondary reinforcer or an increased total reinforcer (primary plus secondary) should make the $\mathrm{C}$ subjects more resistant to disruption (e.g., satiation, extinction) than the $R$ subjects. This result was shown by Roberts et al. (1984). Third, the finding that the cue-food occurrence for the $\mathrm{C}$ subjects must be response contingent (Hall et al., 1981) is also explained by our hypothesis: In order to function as a secondary reinforcer in this context, that is, affect the degree of response learning, the cue must be contingent on the response. A fourth fact explained by this hypothesis is the finding that $R$ subjects respond faster than $C$ animals when trained on a VI schedule with a 0 -sec delay between the operative response and reward (e.g., see Pearce \& Hall, 1978, Experiment 5). That is, simultaneous and immediate presentation of both cue and food following the rewarded response leads to a lower response rates in $\mathrm{C}$ subjects. This result would not be expected if immediate secondary reinforcement was selectively strengthening IRT values, but it could be explained by assuming that $\mathrm{C}$ subjects receive a greater net reward (primary plus secondary) than do $\mathrm{R}$ animals.

Unfortunately there are some salient facts that are not well explained by the notion of secondary reinforcement (or potentiation for that matter). For instance, better learning as a result of immediate secondary reinforcement should affect subjects' responding on a VR schedule just as much as it affects subjects' responding on a VI schedule. Tarpy et al. (1983) and Roberts et al. (1984), however, have not shown any effect of a correlated cue on VR responding (see also Dickinson, Peters, \& Shechter, 1984). Indeed, the present data confirm even more strongly the notion that a C-R rate difference depends on the presence of a temporal contingency: When a ratio schedule was used in Experiment 2 but a time constraint was also in effect, a C-R difference was obtained. Parenthetically, it cannot be argued that the lack of a C-R difference on ratio schedules is due to a ceiling effect, since the average response rates in Experiment 2 of this paper were at least as high as those found in previous studies employing VR schedules. In short, the presence of a temporal contingency seems to be a necessary condition for the correlated signal to operate as it does.

The data reported here are also not consistent with the suggestion made by Tarpy et al. (1983) and Dickinson et al. (1984), that failures to obtain the C-R difference with ratio schedules might be due to short S-US intertrial intervals (ITIs) which produce weak S-US associations (e.g., Gibbon, Baldock, Locurto, Bold, \& Terrace, 1977). Naturally, if overshadowing were involved in this paradigm, weak levels of Pavlovian conditioning would produce little or no S-R overshadowing. But, clearly, such a factor cannot account for the present data: The S-US ITIs on the DRH schedule (approximately $20 \mathrm{sec}$ ) were not appreciably different from those found on the VR schedules employed in previous experiments ( $30 \mathrm{sec}$ in Tarpy et al., 1983; $15 \mathrm{sec}$ in Roberts et al., 1984), and yet, in the present experiment, the $C$ subjects differed from the $\mathrm{R}$ animals. Moreover, the direction of the $\mathrm{C}-\mathrm{R}$ difference was opposite to what any overshadowing theory would predict.

In summary, there are at least three mechanisms by which the food-related cue may have enhanced learning in this paradigm: (1) by improving discrimination learning through accentuating predictors of food, such as the passage of time, which are external to the subject; (2) by potentiating conditioning between the response and food; or (3) by functioning as a secondary reinforcer. We believe that further research is necessary before we can choose among these options. 
Finally, as a small footnote to the issue of response efficiency, we suggest that optimal foraging theorists who have offered more formal statements of response efficiency (e.g., Krebs, 1978; Pyke, Pulliam, \& Charnov, 1977) might well profit from a more detailed consideration of the subject's learning levels (or, more precisely, of variables, such as signaled reward, which contribute to the strength of learning). While some learning theorists (e.g., Tarpy, 1982) and ethologists (e.g., Hollis, 1982; Kamil \& Yoerg, 1982) have recognized that Pavlovian processes may play a crucial role in natural behavior patterns such as those involved in foraging, much of the literature on optimal foraging has viewed learning as an unlikely alternative, rather than a complementary process, to optimal foraging (e.g., Krebs, Ryan, \& Charnov, 1974).

\section{REFERENCES}

Dickinson, A., Peters, R. C., \& Shechter, S., (1984). Overshadowing of responding on ratio and interval schedules by an independent predictor of reinforcement. Behavioural Processes, 9, 421-429.

GaGE, F. H., Evans, S. H., \& Olton, D. S. (1979). Multivariate analyses of performance in a DRL paradigm. Animal Learning \& Behavior, 7, 323-327.

GALEF, B. G., \& OsBorNe, B. (1978). Novel taste facilitation of the association of visual cues with toxicosis in rats. Journal of Comparative and Physiological Psychology, 92, 907-916.

Gibbon, J., Baldock, M. D., Locurto, C., Bold, L., \& Terrace, H. S. (1977). Trial and intertrial durations in autoshaping. Journal of Experimental Psychology: Animal Behavior Processes, 3, 264-284.

HALL, G. (1982). Effects of a brief stimulus accompanying reinforcement on instrumental responding in pigeons. Learning and Motivation, 13, 26-43.

Hall, G., Channell, S. \& Pearce, J. M., (1981). The effects of a signal for free or for earned reward: Implications for the role of response-reinforcer associations in instrumental performance. Quarterly Journal of Experimental Psychology, 33B, 95-107.

Hollis, K. L. (1982). Pavlovian conditioning of signal-centered action patterns and autonomic behavior: A biological analysis of function. In J. S. Rosenblatt, R. A. Hinde, C. Beer, \& M.-C. Busnel (Eds.), Advances in the study of behavior (Vol. 1, pp. 1-64). New York: Academic Press.

KAMIL, A. C., \& YoERG, S. I. (1982). Learning and foraging behavior. In P. P. G. Bateson \& P. H. Klopfer (Eds.), Perspectives in ethology (Vol 5, pp. 325-364). New York: Plenum.

KRAMER, T. J., \& RiLLING, M. (1970). Differential reinforcement of low rates: A selective critique. Psychological Review, 74, 225-254.

KreBs, J. R. (1978). Optimal foraging: Decision rules for predators. In J. R. Krebs \& N. B. Davies (Eds.), Behavioural ecology, an evolutionary approach (chap. 2). Oxford: Blackwell Scientific Publications.

Krebs, J. R., Ryan, J. C., \& Charnov, E. L. (1974). Hunting by expectation or optimal foraging? A study of patch use by chickadees. Animal Behavior, 22, 953-964.
Lattal, K. A., \& Ziegler, D. R. (1982). Briefly delayed reinforcement: An interresponse time analysis. Journal of the Experimental Analysis of Behavior, 37, 407-416.

Mackintosh, N. J., \& Dickinson, A. (1979). Instrumental (type II) conditioning. In A. Dickinson \& R. A. Boakes (Eds.), Mechanisms of learning and motivation: A memorial volume to Jerzy Konorski. Hillsdale, NJ: Erlbaum.

NeVIN, J. A. (1974). Response strength in multiple schedules. Journal of the Experimental Analysis of Behavior, 21, 389-408.

Nevin, J. A., (1979). Reinforcement schedules and response strength. In M. D. Zeiler \& P. Harzem (Eds.), Reinforcement and the organization of behavior (pp. 117-158). New York: Wiley.

PEARCE, J. M., \& HALL, G. (1978). Overshadowing the instrumental conditioning of a lever-press response by a more valid predictor of the reinforcer. Joumal of Experimental Psychology: Animal Behavior Processes, 4, 356-367.

Pyke, G. H., Pulliam, H. R., Charnov, E. L. (1977). Optimal foraging: A selective review of theory and tests. Quarterly Review of Biology, 52, 137-154.

RESCORLA, R. A. (1982). Effect of a stimulus intervening between CS and US in autoshaping. Journal of Experimental Psychology: Animal Behavior Processes, 8, 131-141.

RoberTS, J. E., TARPY, R. M., LEA, S. E. G. (1984). Stimulus-response overshadowing: Effects of signaled reward on instrumental responding as measured by response rate and resistance to change. Journal of Experimental Psychology: Animal Behavior Processes, 10, 244-255.

SHETTLEWORTH, S. J. (1981). Reinforcement and the organization of behavior in golden hamsters: Differential overshadowing of a CS by different responses. Quarterly Journal of Experimental Psychology, 33, 241-255.

Sizemore, O. J., \& LatTal, K. A. (1978). Unsignaled delay of reinforcement in variable-interval schedules. Joumal of the Experimental Analysis of Behavior, 30, 169-175.

St. Claire-Smith, R. (1979). The overshadowing of instrumental conditioning by a stimulus that predicts reinforcement better than the response. Animal Learning \& Behavior, 7, 224-228.

TARPY, R. M. (1982). Principles of animal learning and motivation. Glenview, IL: Scott Foresman.

TARPY, R. M., LeA, S. E. G., \& Midgley, M. (1983). The role of response-US correlation in stimulus-response overshadowing. Quarterly Journal of Experimental Psychology, 35B, 53-65.

TARPY, R. M., RoberTs, J. E., LEA, S. E. G., \& MidG LEY, M. (1984). The stimulus-response overshadowing phenomenon with VI versus FI schedules of reinforcement. Animal Learning \& Behavior, 12, 50-54.

TARPY, R. M., \& SAWABINI, F. L. (1974). Reinforcement delay: A selective review of the last decade. Psychological Bulletin, 81, 984-997.

Williams, B. A. (1975). The blocking of reinforcement control. Journal of the Experimental Analysis of Behavior, 24, 215-227.

Williams, B. A. (1978). Information effects on the response-reinforcer association. Animal Learning \& Behavior, 6, 371-379.

Williams, B. A., \& HeYneman, N. (1982). Multiple determinants of "blocking" effects on operant behavior. Animal Leaming \& Behavior, 10, 72-76.

(Manuscript received June 19, 1984; revision accepted for publication October 25, 1984.) 